\title{
Reflexivity and the Capacity to Think
}

\begin{abstract}
Reflexivity is fundamental to qualitative health research, yet notoriously difficult to unpack. Drawing on Wilfred Bion's work on the development of the capacity to think and to learn, I show how the capacity to think is an impermanent and fallible capacity, with the potential to materialize or evaporate at any number of different points. I use this conceptualization together with examples from published interview data to illustrate the difficulties for researchers attempting to sustain a reflexive approach, and to direct attention toward the possibilities for recovering and supporting the capacity to think. I counter some of the criticisms suggesting that reflexivity can be self-indulgent, and suggest instead that self-indulgence constitutes a failure of reflexivity. In the concluding discussions I acknowledge tensions accompanying the use of psychoanalytic theories for research purposes, and point to emerging psychosocial approaches as one way of negotiating these.
\end{abstract}

\section{Keywords}

communication; reflexivity; relationships, research; research, qualitative; self

The complex and subtle nature of qualitative inquiry is at least partly caused by the unavoidable presence of the researcher within and through the research (Holloway \& Biley, 2011). Qualitative health research, in particular, often tackles subjects infused with powerful and sometimes distressing emotions resulting from the experience of illness and the provision of care (Morse, 2010). Reflexivity has emerged as an important means of responding to this complexity, helping researchers to sustain positions of thoughtful self-awareness (Holloway \& Biley; Woodby, Williams, Wittich, \& Burgio, 2011). It is thus a concept with which qualitative health researchers must engage, despite current literature revealing it to be deceptively intricate. The optimal approach of the researcher is held to be a delicate balance of employing self-knowledge without becoming "overemotional or self-absorbed" (Holloway \& Biley, p. 968), yet the mechanisms of exactly how to accomplish this balance are not well understood.

In this article I draw on psychoanalytic theories of how individuals make sense of the social world, and how they make sense of themselves and others, to trouble some of the assumptions underpinning current approaches to reflexivity. Explicating the details of how the capacity to think evolves (Bion, 1962) helps to uncover the operationalization of reflexivity and the kinds of events, circumstances, and characteristics that might influence it. I explore how these ideas illuminate reflexivity in qualitative health research, with an example of muddled distinctions between self and other as well as an example of momentary failure of reflexivity in research interviewing.
I conclude with acknowledgment of unresolved tensions accompanying the use of psychoanalytic theories for research purposes and argue that despite these, the ideas presented here reveal particular points of intervention for researchers seeking a reflexive way of working.

\section{Capturing Reflexivity}

\section{Essence and Complexity}

Trying to capture the essence of reflexivity reveals a complexity less to do with collecting pithy definitions, of which there are many thoughtful and articulate examples, and more to do with grasping a formulation that seems to change shape considerably as it moves across disciplines and schools of thought. Definitions are inevitably colored by the context within which and for which they are written, resulting in a spectrum of descriptions incorporating more or less sociological, philosophical, and/or researchrelated dimensions.

Of the major thinkers who developed theories and applications of reflexivity, three in particular serve to illustrate the key differences in approach. Pierre Bourdieu favored it as a way of guarding against complacent reproduction of

\footnotetext{
'University of Stirling, Stirling, United Kingdom
}

Corresponding Author:

Sarah Doyle, University of Stirling, School of Education, Stirling, FK9

4LA, Scotland, UK

Email: sarah.doyle@stir.ac.uk 
scholars' pet concerns and ideas (Deer, 2008). Anthony Giddens problematized reflexivity as a consequence of modern society and suggested that the constant flow of new information and knowledge creates a kind of collective, perpetual revisioning of social life (Giddens, 1991). George Herbert Mead, father of symbolic interactionism, considered reflexivity a capacity for self-consciousness and thus the core of human nature (Bond \& Bond, 1986). These are only snapshots of substantial and significant bodies of work, but they show how reflexivity has been conceptualized as a methodological issue for research, a collective activity, and an individual capacity.

More recent writers have continued this pattern of conceptualization, with little consensus. Reflexivity has been cast as "arguably a characteristic of all conscious beings, the ability to take oneself as an object of knowledge, or "reflection"' (Benton \& Craib, 2001, p. 185); or, alternatively, "the regular exercise of the mental ability, shared by all normal people, to consider themselves in relation to their (social) contexts and vice versa" (Archer, 2007, p. 4). There is clear disagreement here about whether all or only some people are able to be reflexive. Moreover, Bryman (2008) located reflexivity firmly in the world of social research when he defined it as "reflectiveness among social researchers about the implications for the knowledge of the social world they generate of their methods, values, biases, decisions, and mere presence in the very situations they investigate" (p. 698). This view has echoes of Bourdieu's contention that reflexivity is deployed in a qualitatively different and more sophisticated way by researchers (Deer, 2008; Gray, 2008).

Tracing the effects of these differences prompts questions not only about the nature and purpose of reflexivity but also about its evolution and development. Whether it is painted as a universally inherent characteristic or as a specialized technique has implications for how (and if) it can be learned, refined, and applied. The extent to which reflexivity is understood as an emotionalized process has, on occasion, led to consternation about how best to represent emotional issues in academic writing (Holmes, 2010), and even a warning against "fetishizing reflexivity as a magic tool that can render theoretical reflection redundant" (Karakayali, 2004, p. 361).

Development of symbolic interactionist ideas has been proposed as a fruitful way of addressing these issues (Holmes, 2010), and indeed the focus on how self and others construct meaning through interaction has long informed approaches to reflexivity in research (Charmaz, 1999, 2011). Drawing more extensively on ideas of emotion as a product of relationships and interactions has been suggested (Holmes, 2010), but limitations with this approach remain because of the difficulty locating and attending to individual, intrapersonal processes within a symbolic interactionist framework (Archer, 2003).
Questions about how to be reflexive or how to practice reflexivity persist (Holmes, 2010; Karakayali, 2004; Riach, 2009), and this is the primary focus of this article. These questions are perhaps most clearly articulated by Archer, who stated that there is a need to be "a good deal more precise about the agential processes involved" (2003, p. 9). In this article I show how psychoanalytic ideas implicate thinking, as defined here, as the central agential process involved. I suggest thinking, as defined here, is the means by which reflexivity is accomplished and that the capacity to think, as defined here, is a prerequisite.

\section{Locating Wilfred Bion}

A detailed account of the remarkably diverse range of schools of psychoanalysis and their variations and vicissitudes is beyond the scope of this article; however, it is helpful to at least situate Wilfred Bion's (1897-1979) work and the associated positions of the relational psychoanalytic theories that constitute the bedrock of the ideas here. Relational approaches have a "democratic, co-created view" (Orbach, 2008, p. 27) that steer away from a reductive focus on intrapsychic phenomena at the expense of recognizing the impact of social and cultural experiences (Layton, 2008). These acknowledgments of external influences and the coproduced nature of dynamics in relationships entail a commitment to the social and societal as well as to the intrapsychic (Hollway, 2008). The roots of the relational stance extend down a long list of psychoanalytic theorists who shared interest in some or other of these dimensions, of which Bion was only one (Orbach).

Together with Melanie Klein, Donald Winnicott, and John Bowlby, Bion was one of the major figures in the psychoanalytic field in the postwar period (Holmes, 1993). He focused on parent-infant relationships and the development of the capacity to think and to learn (Bion, 1962), as well as on psychoanalytic theories of the ways groups of people function when they are together (Bion, 1961). It is his work on the development of the capacity to think and to learn that is of key interest to the rethinking of reflexivity here. To understand the origins of thinking, Bion (1962) returned to the earliest development of this capacity, as it emerges between parent and baby. Brown commented that "Bion's contribution is how the infant, in collaboration with his mother, ${ }^{1}$ comes to know reality, gives emotional meaning to his experiences and learns from those experiences" (2011, p. 85). Bion (1962) examined the details of this process of making sense of the world through the relationship between self and other, and showed that acquiring the capacity to think is a process shaped by the quality and nature of experiences as well as individual ability.

The capacity to think emerges as "a developmental achievement, uncertain and reversible" (Alexandrov, 2009, p. 40), and this indicates the potential for it to be facilitated 
or hampered, not just during infancy but also at any number of other points throughout life. In the remainder of this article I explore this impermanent and fallible nature of the capacity to think, and the corresponding questions about how best to sustain reflexivity in research practices.

\section{Developing the Capacity to Think}

Researcher reflexivity is now considered central to the process of qualitative research (Bryman, 2008; Finlay, 2002; Holloway \& Biley, 2011), but there is a wide range of formulations in use, as indicated in the opening sections of this article. It is commonplace to state that the values and experiences of researchers have the potential to influence what they see and understand. Despite this assertion, much less attention is paid to the detail of exactly how experiences shape views, and thus exactly how reflexivity might provide some redress. I suggest that using a psychoanalytic framework of early social development allows researchers to consider the detail of how thinking evolves, the complex difficulties of sustaining a capacity to think and, consequently, of sustaining a reflexive approach.

Although reflexivity is normally associated with language, the processes of making sense of self, other, and the social world begin much earlier (Reid, 1997). Observation of babies and parents confirms that despite an absence of language, babies can be adept at engaging their parents' attention and have ways of communicating their needs (Reid). These observations also indicate that parents can be adept at receiving and understanding these communications, and can in turn communicate with their babies and respond to and meet their needs (Waddell, 2002). Bion (1962) understood the mechanisms of these communications by extending the concept of "projective identification" first identified by psychoanalyst Melanie Klein (Segal, 1979).

Bion suggested that projective identification is "an early form of that which later is called a capacity for thinking" (1962, p. 37). For example, Bion (1962) proposed that when a baby is overwhelmed and cannot make sense of powerful experiences such as pain, fear, or hunger, he or she projects these experiences into the parent so that the parent is able to feel something of them and understand the baby's experience. As the parent experiences (a diluted version of) the baby's distress, he or she employs a capacity to think about it and then manages it for the baby by providing the attention or comfort required. This process is accomplished by means of what Bion called "reverie" (1962, p. 36), the essence of which is a mind that is open and thoughtful, and able to take in these kinds of experiences from the baby. In this way, the baby begins to learn that experiences can be tolerated, thought about, and addressed, and gradually assumes the ability to do this more independently (Waddell, 2002).
These early experiences shape the individual's sense of self, and help to frame ways of relating to others and the wider social world. A representation of the world is formed that can be reworked and modified according to subsequent experiences, but that over time is likely to become a kind of template for interpersonal engagement. In simple terms, self might be construed as interesting, lovable, unpleasant, or boring; the world might be understood as frightening, unpredictable, interesting, or benign; and others might be seen as helpful, absent, or threatening (Waddell, 2002). This perspective can be understood as something like Bourdieu's concept of habitus (Maton, 2008 , p. 50), which refers to the tendencies and dispositions that repeatedly shape perceptions and interactions. Despite the obvious parallels, contemporary psychoanalytic theories take a more optimistic view of individual potential for agency, and hold that even with disadvantageous early experiences, individuals retain the potential to make use of "good enough" (Winnicott, 1989, p. 456) experiences, then revise the template and thereby enjoy more rewarding relations between self, other, and the social world.

Canham captured the enormous importance of this process perfectly when he commented, "Being able to think and to learn has its roots, therefore, in a meeting of minds between mother and baby" (2006, p. 15). Bion used the term container (1962, p. 90) to denote the parent's mind and its containing function as it holds the baby's intolerable experiences before thinking about and helping to process and make sense of them. These early exchanges have resonance in adulthood in two ways. First, they prepare the individual to sustain curiosity and retain thoughtfulness, even when feelings of discomfort or bewilderment threaten to overwhelm (Canham, 2006). Conversely, in the event that there is a failure of the capacity to think, the opportunity for authentic understanding of the social world is significantly diminished because only that which is comfortable, tolerable, and immediately manageable can be known, and that which unsettles cannot be considered (Canham).

Second, in the face of difficult or unsettling feelings or experiences, individuals of any age can potentially retrace their steps to patterns of early communication (Waddell, 2002). In psychoanalytic terms, states of mind refer to complex emotional attitudes or "positions from which life and relationships are experienced" (Waddell, 2002, p. 6). Some particular states of mind can be more strongly associated with specific age groups or developmental stages than others, but can also be found more temporarily in any individual. For example, a frightened "baby self" state of mind might be present in an adult (Waddell). States of mind can fluctuate even within a single interaction, and can be influenced by interpersonal and intrapersonal factors (Waddell). 
What is of key interest is the possibility of a thinking state of mind, which is essentially a "capacity genuinely to take things in, and to use them to develop a truer picture of the-self-in-the-world" (Waddell, 2002, p. 118). It is then feasible to raise questions about states of mind in which thinking is not possible, and authentic contact with the cause of the discomfort is limited or even eliminated to protect and defend against that discomfort (SalzbergerWittenberg, Williams, \& Osborne, 1983).

This supposition has clear implications for all sorts of situations and consequently, the notion of a "containing" relationship has evolved into many different arenas. It is often used to describe a relationship that provides the kind of thinking space that enables development and growth. For example, academic supervisors might provide containment for students as they bring not-quite-formed ideas, sharing dilemmas of not knowing, and opening up new directions of argument. In this way they help students to manage the discomfort associated with not knowing and therefore encourage sufficient openness and confidence to learn anew (Salzberger-Wittenberg et al., 1983). Qualitative health researchers might provide containment for research participants as they hesitate to articulate their experiences, tolerating the discomfort of uncertainty and keeping open minds to allow the unexpected. Talking about issues such as the experience of illness can be harrowing, and containment supports meaningful recognition and understanding (Hollway \& Jefferson, 2000).

\section{Intersubjectivity and Coconstruction}

The capacity to think, as it is conceptualized here, is not only a function of self but emerges from the relationship between both participants (Bion, 1962). Understanding projective identification as a means of communication recognizes that both parties experience the impact of being part of a thinking couple, and that both impart changes that become part of and shape the evolving interaction (Bion, 1962). Intersubjectivity mirrors very closely Bion's (1962) development of projective identification, and can be described as "how the two minds affect, probe, come to know each other, and, through that exchange, create new meaning and/or uncover previously constructed meanings" (Brown, 2011, p. 109). This definition refers to the psychoanalytic setting, but the words apply equally to the practice of qualitative inquiry, which, similarly, seeks understanding of the human experience.

This sharing of experience between self and other has also been characterized as "reflexive embodied empathy" (Finlay, 2005, p. 271) in a compelling account of the researcher perceiving and feeling the felt experiences of the research participant during interviews and observations. The researcher attempts to use these experiences as a source of information to better understand the data collected (Finlay, 2005). It is important to recognize that the very notion of intersubjectivity highlights that research participants can also feel the felt experience of the researcher. If both are "perpetually undergoing some degree of reorganization as [they] are affected by the unconscious communications" (Brown, 2011, p. 9), it is difficult to see where self ends and other begins. This has the potential to become muddled and blurred, and Finlay seemed to confirm this when she concluded, "When I merged with Jenny, was it Jenny I saw or was it myself? Perhaps, in the end, intersubjectivity demands that empathic revelation of an Other and reflexive uncovering of self are inseparable" (2005, p. 289).

I argue that, drawing on the contemporary psychoanalytic theories presented here, the capacity to think emerges as the prerequisite condition for attending to the difficulty illustrated above. In Bion's (1962) account of projective identification between parent and baby, it is the mobilization of the capacity to think that enables the parent to surmise that it is the baby (other) who is hungry and distressed and not the parent (self). Positing the capacity to think in this way serves as a kind of "freeze frame" function, encouraging a focus on the moment-to-moment details of the interaction. Consequently, the reflexive ability to share the feeling is revealed to be essential but not enough. It must be accompanied by the capacity to think, so that the experience can be thought about.

\section{Rethinking Reflexivity A Thinking State of Mind}

In light of the theories presented, I argue that the concept of reflexivity is irrevocably connected with thinking, and with the capacity to think as it is defined here. If the unconscious, preverbal, and intersubjective dimensions of Bion's (1962) theory of thinking are accepted, the notion of reflexivity as "internal conversation" (Archer, 2007, p. 3) is rendered unhelpfully simplistic and perhaps even misleading. Instead, it becomes possible to formulate a concept of reflexivity as both a quality or state of mind and, simultaneously, a practice in which to actively engage.

The practice of reflexivity could be construed as intentional and perhaps a matter of choice, although arguably, accepting the presence of unconscious and intersubjective processes troubles this somewhat. Furthermore, the idea that the practice of reflexivity needs a thinking state of mind in which to operate challenges the notion that it is possible to decide to be reflexive and then simply do it. Theorizing reflexivity from this perspective raises further questions about what kinds of events, circumstances, and characteristics provide optimal conditions. These and the implications for researchers are considered in the following sections. 


\section{Reflexivity for Qualitative Health Research}

Researcher reflexivity, then, is inevitably woven through the ontological and epistemological framework of the research, as well as being alive in the moment-to-moment interactions between researchers and research participants. The theoretical implications of reflexivity raise questions, not only about the extent to which researchers can employ a genuine capacity to think, but also about the extent to which research participants also employ this capacity. Operationalizing reflexivity in any given research project requires attention to the combined effects of all of these interrelated features.

Currently, one approach to addressing this challenge is for researchers to document something of their own perspectives, interests, and position so that readers might evaluate for themselves the potential for bias (Finlay, 2002). Although disclosing this information can help to identify significant conflicts of interest, such as pressure for research findings to meet the expectations of funding organizations, it is arguably less effective at unpacking more subtle phenomena. I suggest this approach is problematic because of its inherent assumptions that the researcher can employ the capacity to think as defined here, and that the researcher need only articulate the rich knowledge of self already possessed.

It is less common to problematize research participants' perspectives in this way, yet if the intersubjective nature of reflexivity is accepted, it follows that research participants play a key role. In practice, this might mean researchers adopt an epistemological stance that privileges collaborative approaches to the collection and analysis of data to coconstruct the research narrative (Jancowski, Clark, \& Ivey, 2000; Underwood, Satterthwaite, \& Bartlett, 2010). It also means resisting the assumption that research participants can employ the capacity to think as defined here, and as before, that rich self-knowledge is already possessed. Both Wengraf (2001), and Hollway and Jefferson (2000) have cautioned that naïve acceptance of participants' responses is fraught with difficulty, for exactly these reasons.

Reflexivity is often posited as a means of ameliorating the tendency for power to be weighted in favor of the researcher (see, for example, Benton \& Craib, 2001; Jankowski et al., 2000; Kelly, 2010), although Enosh and Buchbinder (2005) sounded an interesting note of caution and suggested that this weighting is by no means inevitable and is perhaps likely to fluctuate, for example, even throughout the course of one interview. Their view highlights the importance of moment-to-moment interactions, and is aptly illustrated by the following extract from their study of narrative construction in qualitative interviews. The researcher asked the questions $(\mathrm{Q})$, with answers (A) given by the research participant (Enosh \& Buchbinder, 2005, p. 594):
Q: What do you do if $[\mathrm{x}]$ happens?

A: It almost never happens.

Q: And if it does happen?

A: Then no.

Q: It must have happened.

A: It's rare, very rare.

Q: So let's remember a time it did happen, what did you do?

A: I didn't do anything.

Enosh and Buchbinder (2005) detailed the way that both researcher and research participant were utterly committed to their own version of reality, and also the way that both contributed to the style of the interaction, which they characterized as a power struggle. I would add that this is a striking example of an absence of any thinking state of mind, and that, consequently, reflexivity in this moment-to-moment interaction was impossible. It does not follow that this researcher is always incapable of employing a thinking state of mind, nor that he or she eschews a reflexive approach to research. Similarly, it does not follow that this research participant is always incapable of employing a thinking state of mind. This example also illustrates the question of unconscious and conscious dimensions of reflexivity. It is entirely possible, and perhaps likely, that the researcher embarked on this interview intending a reflexive approach. Arguably, whatever derailed this interaction lay beyond immediate conscious awareness, and is therefore not accessible for consideration.

Recognizing that states of mind can fluctuate opens windows of opportunity to facilitate shifts in the interaction such that the capacity to think is regained. In the extract above, a sensitive and attuned state of mind might have been able to genuinely take in the information communicated from the other instead of doggedly returning information from self, which in turn could not be received. Alternatively, an ability to perceive any attendant discomfort or incomprehension might give enough space and time to stimulate curiosity about the interaction. Note that the first option requires an authentic contact with other, whereas the second requires an authentic contact with self. It is not necessary that either participant knows immediately how to resolve the difficulty, only that there is a willingness to recognize the difficulty and to tolerate it long enough to learn more. In the inimitable words of Waddell, "Creative thought may be undermined by the stirring of feelings of inferiority and defensiveness, by the push towards certainty which obscures further penetration into the area of the unknown" (2002, p. 117). If reflexivity is to be part of research, it must be alive in moment-to-moment interactions like these as well as in the overarching philosophy and design of the project. 


\section{Reflexivity: A Double-Edged Sword?}

Reflexivity is generally presented as something of a double-edged sword, with even enthusiastic devotees conveying strongly worded warnings. Finlay, in particular, expressed concern at the dangers of "endless narcissistic personal emoting, or interminable deconstructions of deconstructions" (2002, p. 226). Holloway and Biley echoed this, reflecting, "Research is not therapy" (2011, p. 974). There have been accusations of "selfindulgence" (Bishop \& Shepherd, 2011, p. 1283), and Potvin, Bissett, and Walz (2010) also cautioned that reflexivity can overemphasize the researcher's experiences and thereby risk eclipsing the experiences of the research participant.

I suggest these supposed challenges of reflexivity are more appropriately reframed as failures of reflexivity in light of the ideas presented in this article. In brief, reflexivity is essentially an intersubjective process operationalized in the context of a thinking state of mind, and the thinking state of mind means having a "capacity genuinely to take things in, and to use them to develop a truer picture of the-self-in-the-world" (Waddell, 2002, p. 118). This surely requires that the researcher maintain awareness of the context, purpose, and focus of the research, which should mitigate risks of excessive focus on self. It also emphasizes the need for thinking about, rather than simply revealing, aspects of self. Consequently, I argue that lengthy disclosures that fail to demonstrate applicable links to the research project have missed the point.

\section{Dilemmas and Tensions}

The relatively unexplored schools of psychoanalytic theory hold considerable potential for interdisciplinary application, but at the same time their unfamiliarity is problematic. Although there are shared interests in understanding the negotiation of relations between self, other, and the social world, ontological and epistemological tensions remain. Perhaps this is at least in part because "the practice of psychoanalysis has not necessitated that clinical psychoanalysts intervene directly in ontological questioning, whether implicitly or explicitly" (Clemens, 2007, p. 185). As a result, uncertainty about philosophical foundations remains, with psychoanalytic theories variously recognized as having positivist overtones (Billig, 1999) or constructivist leanings (Benton \& Craib, 2001).

The role of the unconscious and its influences on researcher reflexivity is another area that would benefit from further consideration, particularly with a view to exploring how researchers might develop skills in bringing unconscious aspects into conscious awareness. It is patently unrealistic to suggest that all qualitative researchers engage in extended psychoanalytic treatment, yet finding ways of drawing on this rich and diverse body of work to enhance researchers' awareness of themselves and the impact they have on the social world need not require such extensive input. Some researchers are already working with psychoanalytic theories to deepen understanding of human experience, using a psychosocial approach to research (Hollway, 2008). Clarke and Hoggett (2009) have gathered together emerging methods and methodologies used in a range of research projects, and proposed psychoanalysis as a discipline ideally suited to further exploration of reflexivity in research practice.

Jervis (2009), in particular, highlighted the parallels between research interactions and clinical psychoanalytical interactions, and detailed her own experiences of finding that her defensive processes blocked her capacity to think about and engage with interview data. Although she acknowledged that personal psychoanalytic treatment can prove advantageous, she also showed that it is not the only way to turn a critical lens and "thinking" mind to one's own part in shaping research (Jervis).

\section{Conclusion}

Undertaking qualitative health research requires thoughtful engagement with the concept of reflexivity, yet it remains an elusive and slippery gathering of sometimes disparate and contradictory ideas. Contemporary psychoanalytic theories have been used here to conceptualize reflexivity as both a state of mind and a practice. More specifically, reflexivity is defined as an essentially intersubjective process operationalized in the context of a thinking state of mind. Theorizing from this perspective shows how the skills and abilities most likely to facilitate reflexivity can evaporate or materialize in response to events, circumstances, and characteristics.

Recognizing these essential dimensions reveals the different points of intervention for researchers seeking a reflexive way of working. Sensitivity to experiences of both self and other, capacity to tolerate uncertainty, and openness to the unexpected are examples of factors that help sustain a thinking state of mind. Attunement to nuances of communication, and appropriately tailored responses, potentiate the likelihood of authentic interactions with the social world. Being clear about the context and aims of the process supports critical application to the particular research project. All of these are required, because although it is clear that emotional and personal experiences are part of reflexivity, it is also clear they are not sufficient. They must be thought about and analyzed, and the analysis used purposefully in the research process. This means weaving reflexivity into the broader ontological and epistemological frame of the research as well as attending to the moment-to-moment interactions between the researcher and others. 


\section{Acknowledgments}

I thank the reviewers, whose thoughtful insights helped improve early drafts of this article.

\section{Declaration of Conflicting Interests}

The author declared no potential conflicts of interest with respect to the research, authorship, and/or publication of this article.

\section{Funding}

The author disclosed receipt of the following financial support for the research, authorship, and/or publication of this article: This article was written as part of a master's program in health research, funded by a school scholarship from the School of Nursing, Midwifery and Health, University of Stirling.

\section{Note}

1. In this article, quotations using the term mother reflect the original authors' language and are not intended to privilege the maternal role in this context. I have used the term parent to emphasize that fathers and other primary caregivers might also engage in the processes described.

\section{References}

Alexandrov, H. (2009). Experiencing knowledge: The vicissitudes of a research journey. In S. Clarke \& P. Hoggett (Eds.), Researching beneath the surface: Psycho-social research methods in practice (pp. 29-49). London: Karnac.

Archer, M. (2003). Structure, agency \& the internal conversation. Cambridge: Cambridge University Press.

Archer, M. (2007). Making our way through the world: Human reflexivity \& social mobility. Cambridge: Cambridge University Press.

Benton, T., \& Craib, I. (2001). Philosophy of social science. Basingstoke, UK: Palgrave Macmillan.

Billig, M. (1999). Freudian repression: Conversation creating the unconscious. Cambridge: Cambridge University Press.

Bion, W. (1961). Experiences in groups. London: Routledge.

Bion, W. (1962). Learning from experience. London: Karnac.

Bishop, E., \& Shepherd, M. (2011). Ethical reflections: Examining reflexivity through the narrative paradigm. Qualitative Health Research, 21, 1283-1294. doi:10.1177/104973231 1405800

Bond, J., \& Bond, S. (1986). Sociology and health care. Edinburgh, UK: Churchill Livingstone.

Brown, L. (2011). Intersubjective processes and the unconscious: An integration of Freudian, Kleinian and Bionian perspectives. East Sussex, UK: Routledge.

Bryman, A. (2008). Social research methods. Oxford: Oxford University Press.

Canham, H. (2006). What makes children want to learn? In B. Youell (Ed.), The learning relationship (pp. 7-19). London: Karnac.
Charmaz, K. (1999). Stories of suffering: Subjective tales and research narratives. Qualitative Health Research, 9, 362-382. doi:10.1177/104973239900900306

Charmaz, K. (2011). Grounded theory methods in social justice research. In N. K. Denzin \& Y. S. Lincoln (Eds.), The Sage handbook of qualitative research (4th ed., pp. 359-380). Thousand Oaks, CA: Sage.

Clarke, S., \& Hoggett, P. (2009). Researching beneath the surface: Psycho-social research methods in practice. London: Karnac.

Clemens, J. (2007). Love as ontology: Psychoanalysis against philosophy. In C. Kerslake \& R. Brassier (Eds.), Origins \& ends of the mind: Philosophical essays on psychoanalysis (pp. 185-201). Belgium: Leuven University Press.

Deer, C. (2008). Reflexivity. In M. Grenfell (Ed.), Pierre Bourdieu: Key concepts (pp. 199-212). Durham, UK: Acumen.

Enosh, G., \& Buchbinder, E. (2005). The interactive construction of narrative styles in sensitive interviews: The case of domestic violence. Qualitative Inquiry, 11(4), 588-617. doi: $10.1177 / 1077800405275054$

Finlay, L. (2002). Negotiating the swamp: The opportunity and challenge of reflexivity in research practice. Qualitative Research, 2(2), 209-230. doi:10.1177/1468794102002 00205

Finlay, L. (2005). "Reflexive embodied empathy": A phenomenology of participant-researcher subjectivity. Humanistic Psychologist, 33(4), 271-292. doi:10.1207/s15473333 thp3304_4

Giddens, A. (1991). Modernity and self-identity: Self and society in the late modern age. Cambridge: Polity Press.

Gray, B. (2008). Putting emotion and reflexivity to work in researching migration. Sociology, 42(5), 935-952, doi: 10.1177/0038038508094571

Holloway, I., \& Biley, F. (2011). Being a qualitative researcher. Qualitative Health Research, 21, 968-975. doi:10.1177/ 1049732310395607

Hollway, W. (2008). The importance of relational thinking in the practice of psycho-social research: Ontology, epistemology, methodology and ethics. In S. Clarke, H. Hahn, \& P. Hoggett (Eds.), Object relations and social relations: The implications of the relational turn in psychoanalysis (pp. 137-162). London: Karnac.

Hollway, W., \& Jefferson, T. (2000). Doing qualitative research differently. London: Sage.

Holmes, J. (1993). John Bowlby and attachment theory. London: Routledge.

Holmes, M. (2010). The emotionalization of reflexivity. Sociology, 44(1), 139-154. doi:10.1177/0038038509351616

Jancowski, P., Clark, W., \& Ivey, D. (2000). Fusing horizons: Exploring qualitative research and psychotherapeutic applications of social constructionism. Contemporary Family Therapy, 22(2), 241-250.

Jervis, S. (2009). The use of self as a research tool. In S. Clarke \& P. Hoggett (Eds.), Researching beneath the surface: Psycho-social research methods in practice (pp. 145-166). London: Karnac. 
Karakayali, N. (2004). Reading Bourdieu with Adorno: The limits of critical theory and reflexivity. Sociology, 38(2), 351-368. doi:10.1177/0038038504040869

Kelly, S. (2010). Qualitative interviewing techniques \& styles. In I. Bourgeault, R. Dingwall, \& R. de Vries (Eds.), The Sage handbook of qualitative methods in health research (pp. 307-326). London: Sage.

Layton, L. (2008). Relational thinking: From culture to couch and couch to culture. In S. Clarke, H. Hahn, \& P. Hoggett (Eds.), Object relations and social relations: The implications of the relational turn in psychoanalysis (pp. 1-24). London: Karnac.

Maton, K. (2008). Habitus. In M. Grenfell (Ed.), Pierre Bourdieu: Key concepts (pp. 49-65). Durham, UK: Acumen.

Morse, J. (2010). How different is qualitative health research from qualitative research? Do we have a subdiscipline? Qualitative Health Research, 20, 1459-1468. doi:10.1177/1049732310379116

Orbach, S. (2008). Democratizing psychoanalysis. In S. Clarke, H. Hahn \& P. Hoggett (Eds.), Object relations and social relations: The implications of the relational turn in psychoanalysis (pp. 25-44). London: Karnac.

Potvin, L., Bissett, S., \& Walz, L. (2010). Participatory action research: Theoretical perspectives on the challenges of researching action. In I. Bourgeault, R. Dingwall, \& R. de Vries (Eds.), The Sage handbook of qualitative methods in health research (pp. 433-453). London: Sage.

Riach, K. (2009). Exploring participant-centred reflexivity in the research interview. Sociology, 43(2), 356-370. doi: $10.1177 / 0038038508101170$
Reid, S. (1997). Psychoanalytic infant observation. In S. Reid (Ed.), Developments in infant observation: The Tavistock model (pp. 1-12). London: Routledge.

Salzberger-Wittenberg, I., Williams, G., \& Osborne, E. (1983). The emotional experience of teaching \& learning. London: Karnac.

Segal, H. (1979). Klein. London: Karnac Books.

Underwood, M., Satterthwaite, L., \& Bartlett, H. (2010). Reflexivity \& minimization of the impact of age-cohort differences between researcher \& research participants. Qualitative Health Research, 20, 1585-1595. doi:10.1177/ 1049732310371102

Waddell, M. (2002). Inside lives: Psychoanalysis \& the growth of the personality. London: Karnac.

Wengraf, T. (2001). Qualitative research interviewing. London: Sage.

Winnicott, D. (1989). The beginnings of a formulation of an appreciation and criticism of Klein's envy statement. In C. Winnicott, R. Shepherd, \& M. Davis (Eds.), Psychoanalytic explorations (pp. 447-456). London: Karnac.

Woodby, L., Williams, B., Wittich, A., \& Burgio, K. (2011). Expanding the notion of researcher distress: The cumulative effects of coding. Qualitative Health Research, 21, 830-838. doi:10.1177/1049732311402095

\section{Bio}

Sarah Doyle, MRes, PGDip, RMN, is a PhD student in the School of Education, University of Stirling, in Stirling, United Kingdom. 